\title{
Serviços de saúde à população carcerária do Brasil: uma revisão bibliográfica
}

\section{Health services to the prison population in Brazil: a literature review}

\author{
Wyara Ferreira Melo \\ Graduada em Enfermagem pela Faculdade Santa Maria (FSM) e Especialista em Urgência e Emergência pela Faculdade \\ São Francisco. E-mail: wyara_mello@ hotmail.com \\ Hamanda Gelça Araújo Costa Saldanha \\ Licenciada em Geografia pela Universidade Federal do Rio Grande do Norte (UFRN) e Bacharela em Administração \\ pela Universidade Estadual do Rio Grande do Norte (UERN). E-mail: hamandinhajp@ hotmail.com \\ Wellington Ferreira de Melo \\ Mestre em Sistemas Agroindustriais, UFCG. E--mail: wellingtonabcd@gmail.com \\ Juciê de Sousa Almeida \\ Mestre em Sistemas Agroindustriais, FIP. E-mail: juciesalmeida@gmail.com
}

Resumo: Ao longo dos anos, o sistema carcerário brasileiro sofreu fortes modificações e vem fazendo a consolidação de dados que ilustram uma nova lógica dentro do contexto da realidade carcerária do país. As estatísticas demonstram um crescimento de mulheres envolvidas com o crime e, por consequência, com o cárcere. Desde o ano de 1984 está previsto em lei o atendimento em saúde a pessoas reclusas em unidades prisionais, embora apenas em 2003 uma portaria interministerial tenha consagrado à necessidade de organização de ações e serviços de saúde no sistema penitenciário com base nos princípios e diretrizes do Sistema Único de Saúde. Com isso o estudo em questão busca realizar uma pesquisa bibliográfica acerca dos serviços de saúde à população carcerária desenvolvidos no Brasil. A revisão de literatura aborda tópicos como o sistema prisional brasileiro, plano nacional de saúde no sistema penitenciário e os serviços de saúde à população carcerária. Conclui-se que somando todos os problemas no sistema penitenciário e as más condições de atendimento a saúde, é necessário que se pense no indivíduo possivelmente saudável não saiam de lá sem ser acometida por uma doença ou apresentando alguma resistência física, e com a saúde no geral fragilizada. Pois, independentemente da natureza da sua penalidade, mantêm acima de tudo o direito da assistência à saúde, uma vez que, mesmo privados da sua liberdade, e são portadores de deveres e direitos humanos, inerentes à sua cidadania, em que lhes sejam oferecidas condições saudáveis, como a ética, o valor da vida, o corpo, autoimagem e autoestima, para que assim reflitam sobre a pena recebida e que sejam tratados e acolhidos com humanidade, sendo vistos não apenas como alguém que cometeu algum delito, mas sim holisticamente, como seres humanos.

Palavras-chave: Serviço penitenciário. População Carcerária. Saúde Pública.

\begin{abstract}
Over the years, the Brazilian prison system suffered severe modifications and has been doing the consolidation of data illustrating a new logic within the context of the prison reality of the country. Statistics show an increase of women involved in the crime and, consequently, to the prison. Since the year 1984 is provided for by law in health care to inmates persons in prisons, although only in 2003, a ministerial decree has established the need for organizing health actions and services in the prison system based on the principles and system of guidelines Single Health. With this, the present study seeks to accomplish a bibliographical research about the health services to the prison population developed in Brazil. The literature review covers topics such as the Brazilian prison system, national health plan in the prison system and health services to the prison population. We conclude that adding all the problems in the prison system and the poor conditions of care for health, it is necessary to think about possibly healthy individual does not get out of there without being affected by a disease or showing some stamina, and health in General fragile. For, whatever the nature of its penalty, maintain above all the right of health care, since even deprived of their liberty, and are duty bearers and human rights, inherent in citizenship, where their conditions are offered healthy, such as ethics, the value of life, the body, self-image and self-esteem, so that we reflect on the penalty received and that they are treated and welcomed humanely, being seen not just as someone who committed a crime, but holistically, like humans.
\end{abstract}

Keywords: prison service. Prison population. Public health. 


\section{INTRODUÇÃO}

O Brasil, nos últimos anos, vem fazendo a consolidação de dados que ilustram uma nova lógica dentro do contexto da realidade carcerária do país. As estatísticas demonstram um crescimento de mulheres envolvidas com o crime e, por consequência, com o cárcere. O Departamento Penitenciário Nacional do Ministério da Justiça, Depen/MJ, traz um demonstrativo dos primeiros seis anos da década passada, de 2000 a 2006, explicitando o aumento da população prisional feminina de $135,37 \%$, contra uma taxa de $53,36 \%$ do sexo masculino (BITENCOURT, 2012).

Brasil (2010) mostra que desde o ano de 1984 está previsto em lei o atendimento à saúde de pessoas reclusas em unidades prisionais, embora apenas em 2003 uma portaria interministerial tenha consagrado à necessidade de organização de ações e serviços de saúde no sistema penitenciário com base nos princípios e diretrizes do Sistema Único de Saúde (SUS).

Entre a Lei de Execução Penal (LEP) - Lei no 7.210, de 11 de julho de 1984 - e o Plano Nacional de Saúde no Sistema Penitenciário (PNSSP) - Portaria Interministerial $\mathrm{n}^{\circ}$ 1.777, dos Ministérios da Saúde e da Justiça, de 9 setembro de 2003 - houveram dois marcos legais inestimáveis para a garantia do direito à saúde para as pessoas privadas de liberdade: a Constituição da República Federativa do Brasil, de 1988, e a Lei n ${ }^{\circ}$.080, de 19 de setembro de 1990, que institui o SUS. Ao longo dessas últimas décadas, houve uma mudança na sensibilidade governamental em relação às pessoas privadas de liberdade, a ponto de se realizar essas e outras normativas no sentido de assegurar o direito à saúde dessa parcela da população brasileira (BRASIL, 2010).

De acordo com o Conselho Nacional da Justiça (CNJ, 2014), a população confinada no Sistema Penitenciário da Paraíba está estimada em cerca de 9.270 indivíduos. E no Brasil esse número é de 563.526, atingindo um ranking de $4^{\circ}$ lugar entre os 10 países com maior a população prisional.

Então, os fatores que vêm contribuindo para que as mulheres se insiram no mundo da criminalidade, é a ausência do Estado brasileiro como promotor de direitos e qualidade de vida, são vítimas da violência sexual, inferiorizadas e abusadas na guerra de quadrilhas, na exploração sexual, no tráfico de drogas, na prostituição.

Colombaroli (2011) ressalta que quando se volta o foco para a detenção do sexo feminino, a distância entre teoria e prática é ainda maior. O princípio da igualdade é, inúmeras vezes, simplesmente ignorado, notadamente sob o falso argumento de proteção de mulher custodiada contra abusos sexuais ou sua exposição, mesmo quando se refere ao exercício da livre disposição da própria sexualidade.

Desse modo, Santos et al., (2013), acrescentam que a atenção à saúde da população do sistema prisional, se encontra inserida no SUS, visando proteger a população daqueles que possam representar algum tipo de ameaça ou de perigo.

Diante dos dados expostos, e visto que a população que se encontra sob esse regime de confinamento possui importância epidemiológica e sanitária, faz-se necessário investigar como está o sistema carcerário, sobretudo no que se refere ao direito à saúde, e com isso, nos remete a seguinte indagação: Quais os serviços de saúde à população carcerária desenvolvidos do Brasil?

Com isso o estudo em questão busca realizar uma pesquisa bibliográfica acerca dos serviços de saúde à população carcerária desenvolvidos no Brasil.

\section{METODOLOGIA}

A pesquisa se trata de um estudo bibliográfico realizado a partir da seleção de artigos, oriundos do banco de dados de Revistas e outras publicações literárias, datadas dos períodos de 2005 a 2015.

No que se refere ao estudo bibliográfico, Cervo; Bervian; Silva (2007), relatam que praticamente todo o conhecimento humano pode ser disponível em livros ou em outros impressos. Quanto à natureza, esses documentos bibliográficos podem ser: primários - quando coletados em primeira mão, como pesquisa de campo, testemunho oral, depoimentos, entrevistas, questionários, laboratórios; secundários - quando são colhidos em relatórios, livros, revistas, jornais e outros impressos, magnéticos ou eletrônicos.

\section{REVISÃO BIBLIOGRÁFICA}

\section{Sistema Prisional Brasileiro}

Antes de nos reportarmos ao Sistema Prisional Brasileiro, é interessante que compreendamos o seu processo histórico, bem como o seu significado. Assunção (2010) destaca que a palavra prisão tem origem na palavra em latim, prensione, que por sua vez é oriunda da palavra prehensione, que significa prender ou capturar alguém. Seu significado também refere-se ao local que mantém o individuo preso. A palavra possui alguns significados, como, claustro, cadeia, cárcere ou ainda pode ser entendida como privação da liberdade.

Para Carvalho et al., (2006), a pessoa que se encontra na prisão apresenta ruptura dos vínculos sociais em várias dimensões e o sistema prisional aprofunda essa realidade: o isolamento, a invasão da privacidade e a dominação total sobre o sujeito segregado. As vulnerabilidades aparecem também mediante a superlotação, da disseminação de doenças, do uso de drogas, da violência entre os internos e daquela utilizada em nome da manutenção da ordem.

O Direito Penal, até o século XVIII, era marcado por penas cruéis e desumanas, não havendo até então a privação de liberdade como forma de pena. No Brasil, até 1830, não tinha um Código Penal próprio por ser ainda uma colônia portuguesa, submetendo-se às Ordenações Filipinas, que trazia o rol de crimes e penas que seriam aplicados no Brasil. Entre as penas, previam-se as de morte, degrado para as galés e outros lugares, penas corporais (açoite, mutilação, queimaduras), confisco de bens e multa e ainda penas como humilhação pública do réu (MARTILNELLI, 2012).

O autor supracitado salienta que apenas no final do XVIII começaram a surgir os primeiros projetos do que se tornariam as penitenciárias. Primeiro com John Howard 
(1726-1790) que foi o responsável por fazer uma crítica à realidade prisional da Inglaterra e propor uma série de mudanças, sendo a principal a criação de estabelecimentos específicos para a nova visão do cárcere. Posteriormente, outro inglês, Jeremy Bentham (1748-1832), viria a contribuir com o melhoramento da condição dos presídios, entre as suas contribuições para a reforma do sistema punitivo, ele era adepto de uma punição proporcional, ou seja, a disciplina dentro dos presídios deve ser severa, a alimentação grosseira e a vestimenta humilhante, mas todo esse rigor serve para mudar o caráter e os hábitos do delinquente.

Com base em estudos de Assunção (2010), a Revolução Francesa foi um importante marco na história contemporânea da nossa civilização, pois, em tese, o povo ganhou mais autonomia e seus direitos sociais passaram a ser reconhecidos. A vida dos trabalhadores urbanos e rurais melhorou significativamente, e do processo revolucionário, originou-se um direito penal humanizado. Nesse período passa a ser estabelecida uma luta frente ao enfraquecimento da violência e do vexame público, que defendia uma pena que exigisse uma reserva legalmente constituída e garantias processuais ao acusado.

Segundo Ribeiro; Silva (2013), somente no final do século XIX, as instituições passaram a preocupar com a internação e a recuperação do preso, diferente da época dos portugueses no início da colonização do Brasil, na qual o objetivo era castigar os detentos. Em meados de 1865, na Província Baiana já havia casos de internação dos presos na Santa Casa de Misericórdia devido a várias doenças, dentre estas se destacavam patologias do sistema respiratório, digestivo, geniturinário, reumáticas, nutricionais, ulcerações, acidentes ou violências.

Para Cunha (2010) o advento da sociedade moderna capitalista e o processo de urbanização e industrialização, fizeram com que as mulheres fossem recrutadas para o mercado de trabalho. Essa nova organização da sociedade possibilitou a ampliação da participação da mulher no meio social, bem como o aumento de sua escolaridade. Tal possibilidade, embora com grandes resistências sociais, fez com que, a partir dos anos de 1920, nascessem às primeiras manifestações femininas no Brasil. A partir dessa década as mulheres passaram a perceber a importância de se ter direitos e lutar pela ampliação de sua cidadania no país.

Tendo por base Assunção (2010), desde o Código Criminal do Império (Lei de 16 de dezembro de 1830), passando pelo Código Penal da República (Decreto n. 7 de 11 de novembro de 1890) chegando ao atual Código Penal (Decreto Lei n. 2.848 de 07 de dezembro de 1940), todos seguiram idêntica orientação no tocante algumas punições, o que por sua vez denota uma tentativa teórica de humanizar a legislação ao longo do processo histórico brasileiro. Para além de uma República, ora ditatorial, ora democrática, na trajetória do país, o que se viu, foi uma implementação jurídica segundo os anseios políticos e econômicos de um determinado grupo social. Vale salientar, que esse processo de humanização ocorreu também através das manifestações populares, dando volume às correntes doutrinárias nacionais redemocratizadoras, culminando na promulgação da chamada Constituição de 1988, que hoje orienta a aplicação do Estatuto Penal.
O Plano Nacional de Saúde no Sistema Penitenciário (PNSSP) foi instituído no ano de 2003 e era voltado para a população penitenciária, para aquelas pessoas que cometeram delitos e já foram julgadas e condenadas, não contemplando uma parcela da população carcerária, qual seja, aquela reclusa nas cadeias públicas, nos distritos policiais e nas delegacias. O PNSSP, desta maneira, passou a ser reconhecido como é uma estratégia para fazer chegar às políticas de saúde à população prisional, contemplando as diversas ações contidas nas políticas nacionais de saúde mental, de saúde da mulher, entre muitas outras (BRASIL, 2010).

As atribuições das unidades prisionais são esclarecidas no art. 81, do Decreto $\mathrm{n}^{\mathrm{o}}$ 28.212, de 16 de agosto de 2007. Aos órgãos de execução do Sistema Penitenciário, diretamente subordinados à Subsecretaria do Sistema Penitenciário, compete:

I - custodiar internos, em cumprimento de penas restritivas de liberdade, provisórios e submetidos às medidas de segurança, velando pela correta e efetiva aplicação das disposições de sentença ou decisão criminal, de acordo com o que estabelece a legislação vigente e os tratados internacionais pertinente;

II - dirigir, coordenar e controlar a execução das competências dos setores que lhe são subordinados;

III - manter canal de comunicação com órgãos e entidades ligados à execução penal e, em especial, com a Vara de Execuções Criminais;

V - confeccionar a documentação pertinente e providenciar a apresentação de internos às autoridades competentes;

$\mathrm{V}$ - propor normas sobre direitos e deveres dos internos, segurança das instalações, práticas educativas e profissionalizantes, a serem submetidas à avaliação da Subsecretaria;

VI - exercer outras atividades que lhe forem cometidas (ARAUJO, 2009, p. 31-32).

De acordo com Ribeiro; Sousa (2013) as rebeliões ocorridas cada vez mais frequentemente também são uma busca de melhores condições do sistema prisional. Mas o problema da superlotação poderá ser diminuído com a Lei $n^{\circ}$ 12.736/ 2012, na qual cita que o tempo de prisão provisória ou medida de segurança cumprida pelo réu deverá ser considerado pelo juiz na sentença condenatória, o que contribuirá para que as pessoas não fiquem presas por tempo superior àquele previsto na lei. De 2011 até 2013 houve um aumento de cerca 14 mil presos em todo o País perfazendo um total de 218.437 mil réus em situação de prisão provisória.

O crescimento da taxa de encarceramento foi bem mais alarmante entre o público feminino, $135,37 \%$ entre 2000 e 2006, número muito superior ao crescimento do encarceramento masculino, que no mesmo período sofreu um incremento de 53,36\%. Observa-se a relevância de se ter estudos que apresentem esse novo cenário e que considerem a perspectiva de gênero no ambiente prisional, 
garantindo que não haja a invisibilidade das necessidades e direitos das mulheres presas (FRANÇA, 2014).

De acordo com os dados do Escritório das Nações Unidas sobre Drogas e Crimes, há usualmente poucos serviços e estruturas destinados as mulheres, por conta do número relativamente pequeno de presas, já que ainda prevalece uma lógica masculina quando se pensa nos espaços prisionais. A oferta de vagas para mulheres no Sistema Prisional é pequena em todo o país. Há aproximadamente 20.231 vagas para mulheres e 286.266 vagas para homens. Outro dado que aponta a falta de estruturas prisionais para as mulheres é que enquanto, entre elas, $13,8 \%$ estão presas no sistema de polícia, o que representa uma situação de maior precariedade em termos de encarceramento, entre os homens essa taxa é de $8 \%$ (UNODC, 2012).

Ribeiro; Silva (2013) dizem que é importante que no sistema prisional haja a atenção a saúde, envolvendo a saúde das pessoas privadas de liberdades e dos cuidadores, sugerindo o uso de processos educativos para trabalhar a prevenção e a promoção da saúde nas unidades prisionais. Estas e outras ações servem para propiciar que aconteça a saúde no Sistema Prisional. Sendo o resultado de um longo e árduo trabalho desenvolvido pelo Ministério da Saúde, Ministério da Justiça, Organização Mundial de Saúde (OMS), Gestores Estaduais, Municipais, Conferências de saúde e tantos outros colaboradores.

Bitencourt (2012) afirma que a falta de políticas públicas penitenciárias acaba permitindo que tantas presas como egressas, se autoculpabilizem por suas condições e sintam-se ameaçadas ou tenham medo, receio das reações da sociedade para com elas. Por isso, é importante que existam políticas públicas penitenciárias específicas para mulheres, onde as mesmas deixem a situação de invisibilidade social, condição em que estão imersas há algumas décadas.

Em geral, as presidiárias apresentam consigo a marca da miséria, por possuir uma desigualdade socioeconômica, com isso carrega consigo um estigma, com sua entrada na prisão recebem uma cicatriz de criminosa que levarão por toda sua vida, mesmo após a liberdade (ARAÚJO et al. 2014).

Considerando que a grande parte dessas presidiárias encontrava-se grávidas durante o seu envolvimento com o crime, o próximo tópico irá discutir o Plano Nacional de Saúde no Sistema Penitenciário, dando ênfase a saúde e a reprodução feminina.

\section{Plano Nacional de Saúde no Sistema Penitenciário}

Fernandes; Righetto (2013) explicam que o Sistema Penitenciário Brasileiro trata-se do local onde o condenado cumpre a pena imposta pela Lei e aplicada pelo Juiz e, é sabido que este é alvo de grandes discussões, críticas e muitos problemas, como a superlotação, a higiene e saúde, as rebeliões, a não aplicabilidade do princípio da dignidade da pessoa humana, os quais impossibilitam a ressocialização do detento ao convívio social, tendo em vista o descaso e a situação em que os mesmos estão submetidos dentro das prisões.

Com relação a falta de assistência à saúde, Araujo Filho et al., (2014) dizem que esse é um dos aspectos de gravidade relevante que afeta o sistema prisional brasileiro. Em geral, esse quadro está associado às más condições de vida no ambiente carcerário, onde as celas são predominantemente mal ventiladas e superlotadas. A precariedade e insalubridade constituem a maioria dos cenários dos presídios, de modo que favorece a proliferação de diversas patologias, contribuindo para o agravamento das condições de saúde desse público. No que se refere ao encarceramento da população feminina, a situação é ainda mais severa, em virtude da ausência de políticas específicas para o atendimento à mulher privada de liberdade.

Para Rocha e Lodi (2013) é responsabilidade do Estado, além da assistência material, as assistências: à saúde; jurídica; educacional; social; e, religiosa. Também está previsto na Lei de Execução Penal (LEP) o direito dos presos, sendo estes homens ou mulheres, à integridade física e moral, sendo que na Constituição Federal este direito está disposto no inciso XLIX do seu artigo $5^{\circ}$.

Araújo (2009) diz que as políticas do SUS, voltadas à mulher objetiva a responsabilização do sistema pela promoção da qualidade de vida da população feminina, estimulando esse segmento a ampliar seus conhecimentos sobre seus direitos, na área da saúde, e conhecimentos sobre sexualidade e cuidados com o corpo. Desenvolvida sob coordenação da Área Técnica de Saúde da Mulher do Ministério da Saúde (MS), a Política Nacional de Atenção Integral à Saúde da Mulher contempla ações de promoção de saúde que afetam as mulheres, como o câncer de colo do útero, câncer de mama, violência contra a mulher, gravidez de alto risco, dentre outros.

De acordo com o Ministério da Saúde, a Portaria Interministerial n. ${ }^{\circ}$ 1.777, de 9 de setembro de 2003, que instituiu o Plano Nacional de Saúde no Sistema Penitenciário, prevê a inclusão da população penitenciária no SUS, garantindo que o direito à cidadania se efetive na perspectiva dos direitos humanos. $\mathrm{O}$ acesso dessa população a ações e serviços de saúde é legalmente definido pela Constituição Federal de 1988, pela Lei n. ${ }^{\circ}$ 8.080 , de 1990, que regulamenta o SUS, pela Lei n. ${ }^{\circ}$ 8.142 , de 1990, que dispõe sobre a participação da comunidade na gestão e pela Lei de Execução Penal n. ${ }^{\circ}$ 7.210, de 1984. Os instrumentos de gestão do sistema que orientam o planejamento e a tomada de decisão de gestores de saúde estão presentes nesse plano, a exemplo do cadastramento de Unidades dos Estabelecimentos Prisionais no Cadastro Nacional dos Estabelecimentos de Saúde (BRASIL, 2005).

Sousa et al. (2013) salienta que a saúde, no Sistema Penitenciário brasileiro, apresenta um quadro preocupante devido a vários fatores que evidenciam alguns problemas, como, por exemplo, o déficit de vagas nas penitenciárias e, principalmente, a falta de uma assistência médicojurídica adequada e suficiente. Ressalta-se que o país tem a oitava maior população carcerária por habitante e o número de presos aumentou consideravelmente nos últimos anos. Em 1995, eram 148.760 mil presos no país. Até junho de 2009, havia 419.551 mil detidos em penitenciárias e delegacias. Em 1995, a proporção era de 95 presos para cada 100 mil habitantes. Posteriormente o número aumentou chegando a 227 presos para cada 100 mil habitantes.

No que se refere às mulheres presidiarias, Araújo et al., (2014) destacam que no Brasil entre os períodos de 
fevereiro e março de 2008, 1,24\% das mulheres presas encontravam-se grávidas. Neste mesmo período, existiam $0,91 \%$ de mulheres encarceradas amamentando, 1,04\% das presidiárias possuíam filhos em sua companhia, e que o tempo de permanência com a mãe na prisão variava entre quatro meses e sete anos de idade. Sendo assim, Welter (2013) ressalta que o aleitamento materno representa um "tempo extra" para a mãe e o filho ficarem juntos, um tempo em que o bebê pode observar e aprender a conhecer o rosto de sua mãe e sentir-se perto, aquecido e protegido.

Outros fatores que dificultam o ciclo gravídico no sistema prisional podem ser apresentados, como: o afastamento da família; a incerteza de seu futuro na instituição; a vivência num ambiente sentido como ameaçador; o medo de se vincular ao filho e depois ter que se separar, pelo menos temporariamente; o medo e/ou culpa por eventualmente serem ou terem sido usuárias de drogas e comprometerem a saúde dos bebês, entre outros (MARIN, 2011).

Welter (2013, p.21) discorre que:

Estando a detenta grávida, observado deve ser que o stresse a prisão é somado aos abalos emocionais pré-existentes na condição gravídica, o que ocasiona, não raramente, uma desestabilização emocional. Os problemas de origem psíquicos sofridos pela reclusa gestante no ambiente prisional tais como brigas diárias entre as detentas e a má acomodação, atingem diretamente à formação do feto. $\mathrm{Na}$ Penitenciária a grávida perde a sua privacidade, está permanentemente exposta aos olhares dos outros, no pátio, na cela e nos corredores. Dorme ao lado de companheiras que não escolheu, muitas vezes indesejáveis, não decide o que vai comer, qual o horário, o que vai fazer. Portanto, a grávida presa sente-se constantemente humilhada, submissa e despojada de seus sentimentos e desejos pessoais. Assim, percebe-se que a presa, enquanto gestante, tende a absorver em maior escala o estressor social terrível que é o ambiente carcerário.

Para que esse processo seja acompanhado da melhor forma possível, é necessário que os profissionais de saúde, como é o caso do enfermeiro se façam presentes nesse contexto. Desse modo, o tópico a seguir tem como finalidade apresentar o processo de enfermagem no presídio e como o enfermeiro lida com essas situações tão extremas e delicadas.

\section{Serviços de Saúde à População Carcerária}

Atualmente, o sistema prisional é considerado um problema de saúde pública em potencial no mundo todo. $\mathrm{O}$ que pode ser explicado pelo fato das prisões concentrarem indivíduos negros e pobres que não puderam atingir os patamares mínimos para o acesso a bens culturais e/ou de serviços, eles participam do grupo dos "especialmente vulneráveis" às doenças infecto- contagiosas. O confinamento aumenta o risco de algumas infecções relacionadas às práticas sexuais e/ou ao uso de drogas injetáveis. É particular a preocupação com a alta soro prevalência para HIV, de marcadores para as hepatites B e C e outras doenças de transmissão sexual e sanguínea (CARVALHO et al., 2006).

Segundo Fernandes; Righetto (2013) a Lei de Execução Penal determina que os mesmos tenham acesso a diversos tipos de assistência, inclusive assistência médica, porém, a questão relacionada à assistência médica e saúde do preso é uma das grandes problemáticas do sistema carcerário, pois se sabe que na prática, este benefício não é oferecido de forma ampla e correta, tendo em vista que os detentos obtém assistência médica em nível mínimo. Inúmeras doenças tomam conta do ambiente prisional, e, ao negar o tratamento adequado aos presos, o sistema além de ameaçar a vida destes, também facilita a transmissão de diversas doenças à população em geral, através das visitas conjugais e o livramento dos encarcerados, representando um grave risco à saúde pública.

Araujo (2009) aponta que as mulheres são a maioria da população brasileira $(50,77 \%)$ e as principais usuárias do SUS. A vulnerabilidade feminina frente a certas doenças e causas de morte está mais relacionada com a situação de discriminação na sociedade do que com fatores biológicos. Com isso, a Política Nacional de Atenção Integral à Saúde da Mulher (PNAISM) propõe diretrizes para a humanização e a qualidade do atendimento, questões ainda pendentes na atenção à saúde das mulheres.

Com relação ao sistema prisional feminino brasileiro, Cunha (2010), destaca que o mesmo vem sofrendo, nas últimas décadas, um aumento considerável no número de atendimento, mesmo levando em conta a diferença entre a quantidade de mulheres apenadas comparada ao dos homens. Essa política de encarceramento em massa reflete, pois, as consequências de uma sociedade capitalista que marginaliza grande parte da população: enquanto, por um lado, acumula riqueza, por outro, miséria, incerteza, desesperança e violência.

Parafraseando Santos et al., (2013), nos presídios, tanto profissionais quanto pacientes compartilham sentimentos que podem favorecer ou prejudicar o cuidado. Os sentimentos mais comuns são: o medo dos profissionais durante o atendimento aos presidiários, que temendo pela integridade física, tornam-se, por vezes intenso, até mesmo por ser algo próprio do ser humano, que se liga ao instinto de preservação, e acontece independente do querer, que ocorre como garantia contra o perigo. Outro fator que merece ser levado em consideração são os diversos riscos aos quais estes profissionais já estão expostos, como biológicos, químicos e ergonômicos. Soma-se a estes, o lidar com o desconhecido, o adaptar-se ao novo sem um suporte efetivo e continuo que garanta a segurança dos próprios profissionais e pacientes.

Tendo em vista à precariedade da situação de saúde em que se encontram os presos nos dias de hoje, as Regras Mínimas determinam que estes recebam assistência médica básica e, que presos doentes sejam examinados diariamente por um médico, porém, como as autoridades prisionais brasileiras geralmente não prestam serviços de 
assistência médica, sua ausência acaba se tornando uma das principais fontes de reclamações entre os presidiários (FERNANDES; RIGHETTO, 2013).

Para Moreira; Souza (2014) é notório que o déficit na assistência à saúde da população privada de liberdade permanece assombroso. Ao reportarmo-nos diretamente aos grupos vulneráveis socialmente, observa-se que a exclusão se torna ainda maior em relação à população feminina. Percebe-se, ainda, que a política de saúde da mulher não conseguiu estabelecer uma atenção ampliada e direcionada a esses grupos, para suprir suas reais necessidades. Com isso, o país instituiu o PNSSP, que emerge nesse contexto com a finalidade de prover um cuidado integral à saúde da população penitenciária, subsidiando serviços em saúde que assegurem a garantia do direito à cidadania, logo, dos direitos humanos.

Conforme Souza e Passos (2009), o acesso dos presos a ações e serviços de saúde é legalmente garantido pela Constituição Federal de 1988; pela Lei $n^{\circ} 7.210$, de 11 de julho de 1984, que institui a Lei de Execução Penal; pela Lei $\mathrm{n}^{\circ} 8.080$ de 1990 , que regulamenta o SUS e pela Lei ${ }^{\circ} 8.142$ de 1990 , que dispõe sobre a participação da comunidade na gestão do SUS.

Com base em Gois et al. (2012) para que os direitos à cidadania e a atenção a saúde do apenado sejam levados em consideração, a Lei de Execução Penal brasileiro, no título II, capítulo II, art. 14, dispõe que a atenção à saúde do preso e do internado, de caráter preventivo e curativo, deve compreender atendimento médico, farmacêutico e odontológico; e quando o estabelecimento penal não estiver aparelhado para prover tal assistência, é necessário que essa assistência seja prestada em outro local, mediante autorização da direção da instituição.

Souza; Passos (2008) justificam que as ações inerentes à profissão de Enfermagem, sejam elas administrativas ou assistenciais, dadas as especificidades do Sistema Penal, se diferenciam na sua aplicabilidade da realidade extramuros. Para o atendimento das necessidades de saúde da população carcerária, o sistema prisional dispõe de profissionais de saúde nas unidades hospitalares prisionais. Dada a importância da atenção de saúde deste grupo específico, os Ministérios da Justiça e da Saúde instituíram o PNSSP através da Portaria Interministerial $\mathrm{n}^{\circ} 1.777$, de 09 de setembro de 2003 que prevê a inclusão da população penitenciária no SUS, garantindo que o direito à cidadania se efetive na perspectiva dos direitos humanos.

Santos et al., (2013), explicam que a enfermagem tem inerente a sua prática, o cuidar, pois coloca-a como parceira da sociedade, respeitando a dignidade e a individualidade do cliente/paciente, investindo na promoção, manutenção, aquisição e/ou recuperação do estado de equilíbrio físico, mental e social. Sendo assim, percebe-se que os cuidados que a enfermagem outrora disponibilizava a sociedade, tiveram que se adequar as necessidades atuais e, hoje, tem-se o trabalho da enfermagem, em vários cenários e espaços, desempenhando ações preventivas e curativas para clientela, bastante diversificada, como nas comunidades, domicílios, algumas instituições de ensino, plataformas e navios de petróleo, assim como em unidades do Sistema Penal, destinado a pessoas tuteladas pelo Estado.

\section{CONSIDERAÇÕES FINAIS}

Apresentar e discutir um tema tão pouco abordado no nosso cotidiano, torna-se extremamente pertinente, pois, traz a tona uma conjuntura que hora é pouquíssima discutida no contexto da saúde pública

É passível salientar que a atenção à saúde da população do sistema prisional está inserida no SUS, visando proteger a população daqueles que possam representar algum tipo de ameaça ou de perigo.

A partir de toda essa discussão, conclui-se que somando todos os problemas no sistema penitenciário e as más condições de atendimento a saúde, é necessário que se pense no indivíduo possivelmente saudável não saiam de lá sem ser acometida por uma doença ou apresentando alguma resistência física, e com a saúde no geral fragilizada. Pois, independentemente da natureza da sua penalidade, mantêm acima de tudo o direito da assistência à saúde, uma vez que, mesmo privados da sua liberdade, e são portadores de deveres e direitos humanos, inerentes à sua cidadania, em que lhes sejam oferecidas condições saudáveis, como a ética, o valor da vida, o corpo, autoimagem e autoestima, para que assim reflitam sobre a pena recebida e que sejam tratados e acolhidos com humanidade, sendo vistos não apenas como alguém que cometeu algum delito, mas sim holisticamente, como seres humanos.

\section{REFERÊNCIAS BIBLIOGRÁFICAS}

ALENCASTRO, P. L. Mães presidiárias e o direito da criança e do adolescente à convivência familiar. 2015. Disponível em: <http://www3.pucrs.br/pucrs/files/uni/poa/direito/graduac ao/tcc/tcc2/trabalhos2015_1/paola_alencastro.pdf $>$.

ARAUJO FILHO, A. C. A. de; et al. Assistência de enfermagem na saúde sexual e reprodutiva de mulheres reclusas: relato de experiência. 2014. Disponível em: <http://189.59.9.179/CBCENF/sistemainscricoes/arquivos Trabalhos/I52254.E12.T9479.D8AP.pdf >.

ARAÚJO, A. do N. V. de; et al. Percepção de mães presidiárias sobre os motivos que dificultam a vivência do binômio. Revista Enfermagem Contemporânea, v. 3, n. 2, p. 131-142, dez, 2014. Disponível em: <http://www5.bahiana.edu.br/index.php/enfermagem/artic le/view/411/341>.

ARAUJO, L. M. de. Assistência de enfermagem na penitenciária feminina do DF. Universidade Católica de Brasília. Brasília, 2009. Disponível em: <http://repositorio.ucb.br/jspui/bitstream/10869/1795/1/La rissa\%20Martins\%20de\%20Araujo.pdf $>$.

ASSUNÇÃO, C. H. V. de. A saúde da mulher: a situação das encarceradas do Presídio Feminino de Florianópolis. 2010. 64p. Graduação [Monografia]. Universidade Federal de Santa Catarina. Florianópolis, 2010.

BARROS, Ana Maria de; JORDÃO, Maria Perpétua Dantas. A cidadania e o sistema penitenciário brasileiro. Unieducar - Educação sem distância. 2002. Disponível 
em:

$<$ https://www.ufpe.br/ppgdh/images/documentos/anamb1. pdf $>$.

BITENCOURT, Á. H. Mulheres \& sistema prisional: o sentido do trabalho para quem viveu e vive sob a égide do cárcere. 2012. 25p. Dissertação [Mestrado]. Universidade Católica do Rio Grande do Sul. Porto Alegre, 2012.

BRASIL. Legislação em saúde no sistema penitenciário. Ministério da Saúde, Secretaria de Atenção em Saúde, Departamento de Ações Programáticas Estratégicas. Brasília: Ministério da Saúde, 2010.

Ministério da Saúde. Plano Nacional de Saúde no Sistema Penitenciário. Ministério da Saúde, Secretaria de Atenção à Saúde, Departamento de Ações Programáticas Estratégicas. 2 ed. Brasília: Editora do Ministério da Saúde, 2005. Disponível em: <http://bvsms.saude.gov.br/bvs/publicacoes/plano_nacion al_saude_sistema_penitenciario_2ed.pdf $>$.

Resolução no 466, de 12 de dezembro de 2012. Brasília: Conselho Nacional de Saúde, 2013.

CARVAlHO, M. L. de; et al. Perfil dos internos no sistema prisional do Rio de Janeiro: especificidades de gênero no processo de exclusão social. Ciência \& Saúde Coletiva, v. 11, n. 2, p. 461-471, 2006.

CERVO, A.; BERVIAN, P. A.; SILVA, R. Metodologia Científica. 6 ed. São Paulo: Pearson Prentice Hall, 2007.

CHAIM, S. R. P.; OLIVEIRA, S. M. J. V. de; KIMURA, A. F. Hipertensão arterial na gestação e condições neonatais ao nascimento. Acta Paulista de Enfermagem, v. 21, n. 1, p. 53-8, 2008. Disponível em: <http://www.scielo.br/pdf/ape/v21n1/pt_07.pdf>.

CNJ, C. N. de J. Novos diagnósticos de pessoas presas no Brasil. Departamento de Monitoramento e Fiscalização do Sistema Carcerário e Sistema de Execução de Medidas Socioeducativas -DMF. Brasília, jun, 2014.

COLOMBAROLI, A.C.M. Vigilância da dignidade da mulher no cárcere: restrições a visita íntima para a subjetividade feminina. São Paulo, 2011.

CUNHA, E. L. da. R.: O desafio da educação no sistema prisional feminino. Cad. Cedes, Campinas, v. 30, n. 81, p. 157-178, mai.-ago. 2010.

FRANÇA, M. H. de O. Criminalidade e prisão feminina: uma análise da questão de gênero. Revista Ártemis, v. 18, n. 1, p. 212-227, jul-dez, 2014.

FERNANDES, B. R; RIGHETTO, L. E. C. O sistema carcerário brasileiro. Revista Eletrônica de Iniciação Científica, Itajaí, v. 4, n. 3, p. 115- 135, 2013. Disponível em:

<http://www.univali.br/ensino/graduacao/cejurps/cursos/d ireito/direito-itajai/publicacoes/revista-de-iniciacaocientifica-
ricc/edicoes/Lists/Artigos/Attachments/884/bruna-eluiz.pdf>.

FRINHANI, F. M. D.; SOUZA, L. Mulheres encarceradas e espaço prisional: uma análise de representações sociais. Psicol. teor. prat., São Paulo, v. 7, n. 1, jun., 2005. Disponível em: <http://pepsic.bvsalud.org/scielo.php?script=sci_arttext\&p id $=$ S1516-36872005000100006>

GOIS, S. M.; et al. Para além das grades e punições: uma revisão sistemática sobre a saúde penitenciária. Ciência \& Saúde Coletiva, v. 17, n. 5, p.1235-1246, 2012.

MARIN, I. da S. K. Tornar-se mãe num presídio: a criação de um espaço potencial. 2011. Disponível em: $<$ http://carceraria.org.br/wpcontent/uploads/2015/02/Artigo-IsabelMarin_Tornar_se_mae_num_presidio.pdf $>$.

MARTINELLI, J. P. O. A evolução histórica do sistema prisional e a Penitenciária do Estado de São Paulo. Revista Liberdades, n. 11, set-dez, 2012.

MOREIRA, M. A.; SOUZA, H. S. Vivências de mulheres aprisionadas acerca das ações de saúde prestadas no sistema penitenciário. O Mundo da Saúde, São Paulo v. 38 , n. 2, p. 219-227, 2014.

PIMENTEL, J. Relatório da ONU, lançado em abril, mostra que Brasil registrou cerca de $10 \%$ dos homicídios dolosos* ocorridos no mundo em 2012. 2014. Disponível em: <http://dssbr.org/site/2014/05/relatorio-da-onulancado-mundialmente-em-abril-mostra-que-brasilregistrou-cerca-de-11-dos-homicidios-ocorridos-nomundo-em-2012/>.

PRODANOV, C. C; FREITAS, E. C. Metodologia do trabalho científico: Métodos e Técnicas da Pesquisa e do Trabalho Acadêmico. 2 ed. Novo Hamburgo:Feevale, 2013.

RIBEIRO, M. A. de J.; SILVA, I. C. R. da. A saúde no sistema prisional. Pontifícia Universidade Católica de Goiás. 2013.

ROCHA, F. I. F.; LODI, M. Execução penal da mulher internada no presídio regional de Araxá. Revista Jurídica UNIARAXÁ, Araxá, v. 17, n. 16, p. 91-126, ago. 2013. Disponível em: <http://www.uniaraxa.edu.br/ojs/index.php/juridica/article /view/426/405>.

ROCHA, S. O programa Bolsa Família Evolução e efeitos sobre a pobreza. Economia e Sociedade, Campinas, v. 20, n. 1, p. 113-139, abr. 2011. Disponível em: <http://www.scielo.br/pdf/ecos/v20n1/v20n1a05>.

RUDNICKI, D.; PASSOS, G.B. A alimentação das presas na penitenciária feminina Madre Pelletier. Tempo da Ciência, v. 19, n, 37, 2012. 
SANTOS, F. S.; et al. Cuidados de enfermagem em situação de cárcere segundo Waldow: entre o profissional e o expressivo. Rev Eletronic TrimEnfermeria Global, $n$. 31, jul, 2013. Disponível em: <http://scielo.isciii.es/pdf/eg/v12n31/pt_revision2.pdf>.

SOUSA, M. C. P.; et al. Atenção à saúde no sistema penitenciário: revisão de literatura. R. Interd., v.6, n.2, p.144-151, abr.mai.jun. 2013. Disponível em: <http://revistainterdisciplinar.uninovafapi.edu.br/index.ph p/revinter/article/view/59/pdf_32 >.

SOUZA, M. O. da S.; PASSOS, J. P. A prática de enfermagem no sistema penal: limites e possibilidades. Esc Anna Nery RevEnferm, v. 12, n. 3, p. 417-23. Set, $2008 . \quad$ Disponível em: <http://www.scielo.br/pdf/ean/v12n3/v12n3a04>.

WELTER, M. E. A mulher no sistema prisional brasileiro. 2013. 48p. Graduação [Monografia]. Universidade Regional do Noroeste do Estado do Rio Grande do Sul. Santa Rosa, 2013. Disponível em: <http://bibliodigital.unijui.edu.br:8080/xmlui/bitstream/ha ndle/123456789/2102/Maria\%20Estela\%20Welter.pdf?se quence $=1>$. 